\title{
Current estimates of biogenic emissions from eucalypts uncertain for south- east Australia
}

\section{Kathryn M. Emmerson et al.}

Correspondence to: Kathryn M. Emmerson (kathryn.emmerson@csiro.au)

The copyright of individual parts of the supplement might differ from the CC-BY 3.0 licence. 


\section{Construction of high resolution PFT map for Australia}

A new PFT dataset has been constructed for this work, at $3 \mathrm{~km}$ resolution from the International Geosphere Biosphere Project (IGBP) dataset. When emission factor maps are used, as is the case for the major biogenic species isoprene and $\alpha$ - and $\beta$ pinene, the emission rates are not particularly sensitive to this PFT map. Testing the CSIRO-CTM without the emission factor

5 maps would increase the sensitivity to PFT, which could be tested in future work. This could also be a good opportunity to test alternative land cover datasets.

Table S1 gives details of how the IGBP landcover dataset was split into the NCAR 16 PFTs suitable for MEGAN. 
Table S1 Relationship of IGBP landcover types to NCAR PFTs, sorted according to boreal, temperate and tropical biomes.

Not all landcover types are present in Australia.

\begin{tabular}{|c|c|c|c|c|c|}
\hline \multicolumn{3}{|c|}{ IGBP Landcover type } & \multicolumn{3}{|c|}{ NCAR Plant Functional Types } \\
\hline & & $\begin{array}{l}\text { \% Bare } \\
\text { Ground }\end{array}$ & $\begin{array}{l}\text { Boreal } \\
\leq 19^{\circ} \mathrm{C}\end{array}$ & $\begin{array}{c}\text { Temperate } \\
19^{\circ} \mathrm{C} \leq \mathrm{X} \leq 15.5^{\circ} \mathrm{C}\end{array}$ & $\begin{array}{l}\text { Tropical } \\
\geq 15.5^{\circ} \mathrm{C}\end{array}$ \\
\hline $\mathbf{0}$ & Ocean & $100 \%$ & & & \\
\hline 1 & $\begin{array}{l}\text { Evergreen } \\
\text { Needleleaf Forest }\end{array}$ & $25 \%$ & $75 \% \mathrm{Nt} \mathrm{Eg} \mathrm{B}$ & $75 \% \mathrm{Nt} \mathrm{Eg} \mathrm{T}$ & \\
\hline 2 & $\begin{array}{l}\text { Evergreen } \\
\text { Broadleaf Forest }\end{array}$ & $5 \%$ & & $95 \% \mathrm{Bt} \mathrm{Eg} \mathrm{T}$ & $95 \% \mathrm{Bt} \mathrm{Eg} \mathrm{Tr}$ \\
\hline 3 & $\begin{array}{l}\text { Deciduous } \\
\text { Needleleaf Forest }\end{array}$ & $50 \%$ & $50 \% \mathrm{Nt} \mathrm{Dc} \mathrm{B}$ & & \\
\hline 4 & $\begin{array}{l}\text { Deciduous } \\
\text { Broadleaf Forest }\end{array}$ & $25 \%$ & $75 \%$ Bt Dc B & $75 \% \mathrm{Bt} \mathrm{Dc} \mathrm{T}$ & $75 \% \mathrm{Bt} \mathrm{Dc} \mathrm{Tr}$ \\
\hline 5 & Mixed Forest & $26 \%$ & $\begin{array}{l}55.5 \% \mathrm{Nt} \mathrm{Eg} \mathrm{B} \\
18.5 \% \mathrm{Bt} \mathrm{Dc} \mathrm{B}\end{array}$ & $\begin{array}{l}55.5 \% \mathrm{Bt} \mathrm{Eg} \mathrm{T} \\
18.5 \% \mathrm{Bt} \mathrm{Dc} \mathrm{T}\end{array}$ & $\begin{array}{l}55.5 \% \mathrm{Bt} \mathrm{Eg} \mathrm{Tr} \\
18.5 \% \mathrm{Bt} \mathrm{Dc} \mathrm{Tr}\end{array}$ \\
\hline 6 & Closed Shrubland & $20 \%$ & $\begin{array}{l}64 \% \mathrm{Sb} \mathrm{Dc} \mathrm{B} \\
16 \% \mathrm{Gs} \mathrm{C} 3 \mathrm{Cd}\end{array}$ & $\begin{array}{l}32 \% \mathrm{Sb} \mathrm{Eg} \mathrm{T} \\
32 \% \mathrm{Sb} \mathrm{Dc} \mathrm{T} \\
16 \% \mathrm{Gs} \mathrm{C} 3 \mathrm{Cl}\end{array}$ & $16 \%$ Gs C3 W \\
\hline 7 & Open Shrubland & $50 \%$ & $\begin{array}{l}10 \% \mathrm{Sb} \mathrm{Dc} \mathrm{B} \\
40 \% \text { Gs C3 Cd }\end{array}$ & $\begin{array}{c}5 \% \mathrm{Sb} \mathrm{Eg} \mathrm{T} \\
5 \% \mathrm{Sb} \mathrm{Dc} \mathrm{T} \\
40 \% \text { Gs C3 Cl }\end{array}$ & $40 \%$ Gs C3 W \\
\hline 8 & Woody Savannah & - & $\begin{array}{l}30 \% \text { Nt Eg B } \\
10 \% \text { Bt Dc B } \\
60 \% \text { Gs C3 Cd }\end{array}$ & $\begin{array}{l}30 \% \mathrm{Bt} \mathrm{Eg} \mathrm{T} \\
10 \% \mathrm{Bt} \mathrm{Dc} \mathrm{T} \\
60 \% \text { Gs C3 Cl }\end{array}$ & $\begin{array}{l}30 \% \mathrm{Bt} \mathrm{Eg} \mathrm{Tr} \\
10 \% \mathrm{Bt} \mathrm{Dc} \mathrm{Tr} \\
60 \% \text { Gs C3 W }\end{array}$ \\
\hline 9 & Savannahs & - & $\begin{array}{l}7.5 \% \mathrm{Nt} \mathrm{Eg} \mathrm{B} \\
2.5 \% \mathrm{Bt} \mathrm{Dc} \mathrm{B} \\
90 \% \text { Gs C3 Cd }\end{array}$ & $\begin{array}{l}7.5 \% \mathrm{Bt} \mathrm{Eg} \mathrm{T} \\
2.5 \% \mathrm{Bt} \mathrm{Dc} \mathrm{T} \\
90 \% \text { Gs C3 Cl }\end{array}$ & $\begin{array}{l}\text { 7.5\% Bt Eg Tr } \\
2.5 \% \mathrm{Bt} \mathrm{Dc} \mathrm{Tr} \\
90 \% \text { Gs C3 W }\end{array}$ \\
\hline 10 & Grasslands & $20 \%$ & $80 \%$ Gs C3 Cd & $80 \%$ Gs C3 Cl & $80 \%$ Gs C3 W \\
\hline 11 & Permanent Wetland & $100 \%$ & & & \\
\hline & Cropland & $15 \%$ & $85 \%$ Crop & $\begin{array}{l}76.5 \% \text { Crop } \\
8.5 \% \text { Corn }\end{array}$ & $\begin{array}{l}59.5 \% \text { Crop } \\
25.5 \% \text { Corn }\end{array}$ \\
\hline 13 & Urban and Built-Up & $70 \%$ & $\begin{array}{l}\text { 7.5\% Nt Eg B } \\
7.5 \% \mathrm{Nt} \mathrm{Dc} \mathrm{B} \\
5 \% \text { Sb Dc B } \\
10 \% \text { Gs C3 Cd }\end{array}$ & $\begin{array}{c}7.5 \% \mathrm{Bt} \mathrm{Eg} \mathrm{T} \\
7.5 \% \mathrm{Bt} \mathrm{Dc} \mathrm{T} \\
5 \% \mathrm{Sb} \mathrm{Eg} \mathrm{T} \\
10 \% \mathrm{Gs} \mathrm{C} 3 \mathrm{Cl}\end{array}$ & $\begin{array}{l}\text { 7.5\% Bt Eg Tr } \\
7.5 \% \mathrm{Bt} \mathrm{Dc} \mathrm{Tr} \\
10 \% \mathrm{Gs} \mathrm{C} 3 \mathrm{~W}\end{array}$ \\
\hline 14 & $\begin{array}{l}\text { Cropland/Natural } \\
\text { Vegetation Mosaic }\end{array}$ & $15 \%$ & $85 \%$ Crop & $85 \%$ Crop & $85 \%$ Crop \\
\hline 15 & Snow and Ice & $100 \%$ & & & \\
\hline 16 & $\begin{array}{l}\text { Barren or Sparsely } \\
\text { Vegetated }\end{array}$ & $100 \%$ & & & \\
\hline 17 & Water Bodies & $100 \%$ & & & \\
\hline
\end{tabular}

5 Notes: $\mathrm{B}=$ Boreal, $\mathrm{T}=$ Temperate, $\mathrm{Tr}=$ Tropical.

$\mathrm{Nt} \mathrm{Eg} \mathrm{=} \mathrm{needleleaf} \mathrm{evergreen} \mathrm{tree,} \mathrm{Nt} \mathrm{Dc}=$ needleleaf deciduous tree, $\mathrm{Bt} \mathrm{Eg}=$ broadleaf evergreen tree, $\mathrm{Bt} \mathrm{Dc}=\mathrm{broadleaf}$ deciduous tree, $\mathrm{Sb} \mathrm{Eg}=$ evergreen shrub, $\mathrm{Sb} \mathrm{Dc}=$ deciduous shrub, $\mathrm{Gs} \mathrm{C} 3=$ grass $($ can be $\mathrm{Cd}=\operatorname{cold}, \mathrm{Cl}=\mathrm{cool}$ or $\mathrm{W}=\mathrm{warm}$ depending on climatic zone). 


\section{Comparisons with air quality data}

We have tested modelled meteorological, chemical and dilution variables and conclude that there are no confounding influences that distort the model response to BVOCs. Figure S1 shows diurnal cycles of temperature, ozone and NOx where data are available. These comparisons give a broader impression of how the model predicts airshed chemistry, as both ozone and NOx are influenced by urban emissions. Temperature is a major driver of MEGAN and many compound classes exhibit a temperature dependence. The average modelled profiles compare to within 1 or 2 degrees $\mathrm{C}$ of the observations. The modelled ozone profiles are high $(<5 \mathrm{ppb})$ for SPS1 and MUMBA, and low for SPS2. Reducing the isoprene and increasing the monoterpene emission rates has reduced the peak SPS1 modelled ozone concentration by up to 2 ppb more than the peak MUMBA ozone concentration, bringing them more into line with the observations. The shape of the NOx diurnal profiles

10 show that the timing of the morning and evening traffic peaks is correct. However, there is a high bias in modelled NOx during SPS1 which is not present in either SPS2 or MUMBA. The anthropogenic emissions inventory is the same for each of the sites, thus differences are likely due to modelled dilution and mixing heights during SPS1. Modelled NOx in SPS2 shows a high peak during the late afternoon, which is attributed to a collapsing boundary layer occurring too early in the day in the model compared with the observations. There are no direct measurements of boundary layer height for these field campaigns.

15 The model boundary layer height has been compared with vertical potential temperature profiles from aircraft taking off from Sydney airport (AMDAR, http://www.wmo.int/pages/prog/www/GOS/ABO/AMDAR/AMDAR_System.html). From a small sample, the overall profiles compare reasonably well (not shown). However, the aircraft generally take off towards the sea and there is significant horizontal displacement of the plane between the potential temperature readings. We assess that horizontal gradients in temperature and boundary layer height in this coastal region considerably confuse the issue of resolving the boundary layer depth at Westmead, a site $33 \mathrm{~km}$ inland. Thus at this stage boundary layer height verification is not possible.

The increase/reduction in the biogenic VOCs from the emission factor sensitivity test has not changed the diurnal profiles of $\mathrm{NO}_{\mathrm{X}}$ much in Figure S1, although there are small differences at nighttime during SPS1 and SPS2. There is uncertainty in the NOx emissions which affects the airshed chemistry of the modelled domains. A sensitivity test is conducted whereby the NOx emissions associated with motor vehicles, industrial processes and fire sources are scaled by $\pm 20 \%$. Results in Table S2 show the effects of the NOx emissions increase/decrease (and emission factor sensitivity test) on average concentrations of NOx, ozone, xylene and the biogenic species. Larger percentage changes are seen in locations close to anthropogenic sources, i.e. Sydney. Tumbarumba is rural and located far from the influences of urban NOx emissions, thus no effects are observed. Overall a $\pm 20 \%$ change in NOx causes $1-5 \%$ change in isoprene and monoterpene concentrations. Xylene is chosen to represent an anthropogenic primary species, whose concentration is dependent on the availability of oxidant species. The results indicate that changes in the biogenic species and NOx impact on xylene by $1 \%$. There are some unexpected consequences of the non-linearities in the chemical system, i.e. a decrease in ozone should cause an increase in isoprene concentrations at MUMBA. Horizontal advection is also a factor as is the time taken for chemical production of ozone.

The model has been tested against observed concentrations and meteorological data. Sensitivity studies varying NOx and VOC emissions have been conducted to test the robustness of the modelling system. We conclude that there are no confounding influences that distort the model response to BVOCs. 

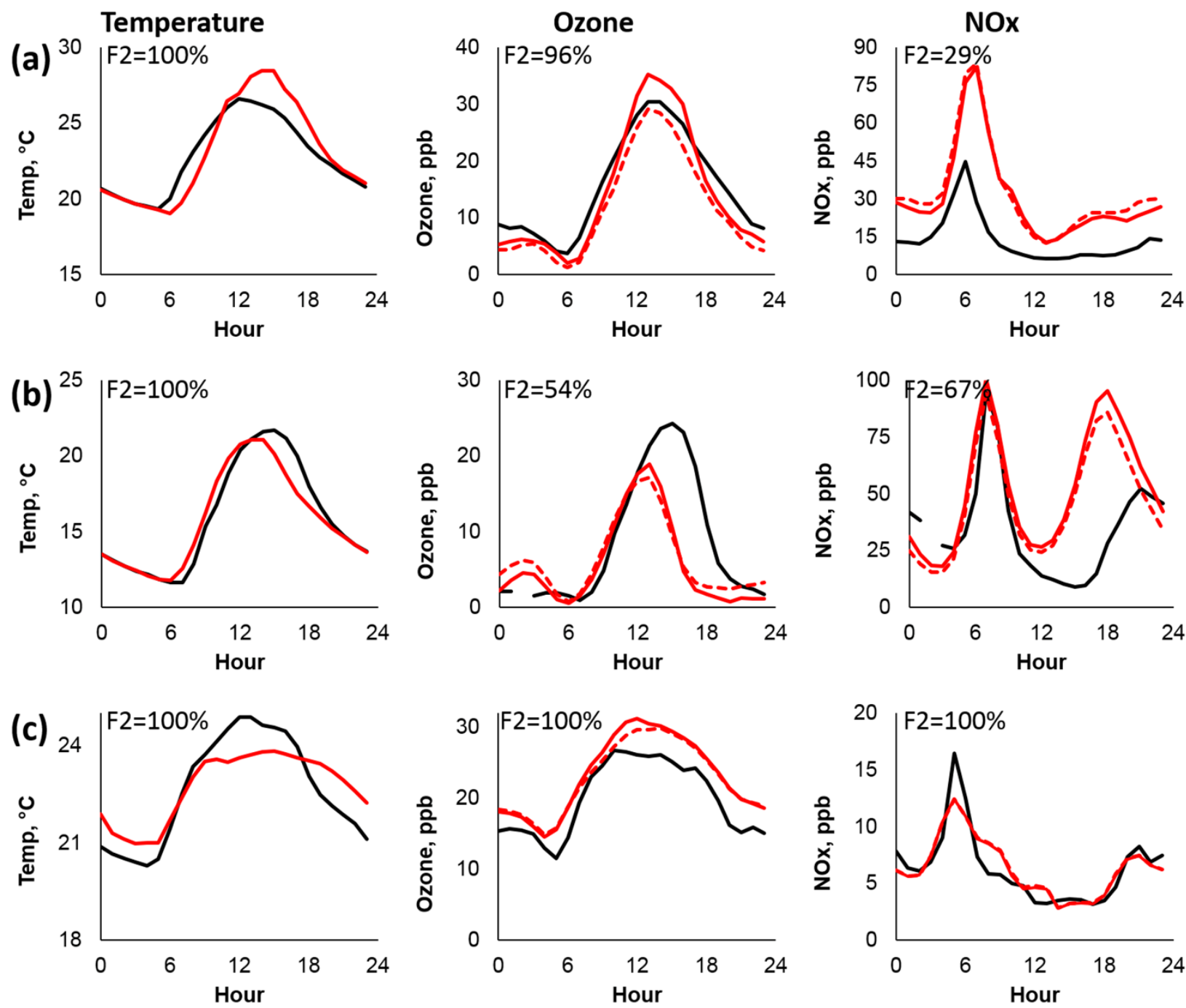

- Observations Modelled Base Case $\quad$ Emission Factor Test

Figure S1 Campaign average diurnal cycles for temperature, ozone and NOx. (a)=SPS1, (b)=SPS2, (c)=MUMBA. F2= percentage within a factor of 2 between observations and base run. 
Table S2 Change in domain average concentrations for the duration of each field campaign. The percentage change from the base run is indicated number in brackets, for the emission factor sensitivity test and changes in anthropogenic NOx emissions.

\begin{tabular}{|l|l|l|l|l|l|l|}
\hline & & Ozone & NOx & Isoprene & Monoterpenes & Xylene \\
\hline \multirow{5}{*}{ SPS1 } & Base & 24.5 & 2.5 & 4.0 & 0.3 & 0.1 \\
\cline { 2 - 7 } & EF test & $23.9(-2 \%)$ & $2.6(2 \%)$ & $1.1(-73 \%)$ & $1.0(207 \%)$ & $0.1(<1 \%)$ \\
\cline { 2 - 7 } & NOx $+20 \%$ & $24.8(1 \%)$ & $3.0(22 \%)$ & $3.9(-2 \%)$ & $0.3(-2 \%)$ & $0.1(<1 \%)$ \\
\cline { 2 - 7 } & NOx $-20 \%$ & $24.2(-1 \%)$ & $2.0(-21 \%)$ & $4.1(3 \%)$ & $0.3(2 \%)$ & $0.1(<1 \%)$ \\
\hline \multirow{5}{*}{ SPS2 } & Base & 19.6 & 3.8 & 0.9 & 0.2 & 0.1 \\
\cline { 2 - 7 } & EF test & $19.2(-2 \%)$ & $3.9(2 \%)$ & $0.3(-70 \%)$ & $0.7(224 \%)$ & $0.1(-1 \%)$ \\
\cline { 2 - 7 } & NOx $+20 \%$ & $19.3(-2 \%)$ & $4.6(22 \%)$ & $0.9(-1 \%)$ & $0.2(-1 \%)$ & $0.1(2 \%)$ \\
\cline { 2 - 7 } & NOx $-20 \%$ & $19.9(2 \%)$ & $3.0(-21 \%)$ & $0.9(2 \%)$ & $0.2(1 \%)$ & $0.1(<1 \%)$ \\
\hline \multirow{5}{*}{ Mumba } & Base & 26.2 & 2.9 & 1.8 & 0.1 & 0.03 \\
\cline { 2 - 7 } & EF test & $25.3(3 \%)$ & $3.0(2 \%)$ & $0.5(-72 \%)$ & $0.4(211 \%)$ & $0.03(<1 \%)$ \\
\cline { 2 - 7 } & NOx $+20 \%$ & $26.1(<1 \%)$ & $3.6(21 \%)$ & $1.7(-2 \%)$ & $0.1(-3 \%)$ & $0.03(2 \%)$ \\
\cline { 2 - 7 } & NOx $-20 \%$ & $26.2(<1 \%)$ & $2.3(-21 \%)$ & $1.8(3 \%)$ & $0.1(1 \%)$ & $0.03(<1 \%)$ \\
\hline \multirow{5}{*}{ Tumba. } & Base & 18.4 & 0.4 & 0.7 & 0.2 & 0.009 \\
\cline { 2 - 7 } & EF test & $18.3(<1 \%)$ & $0.3(-4 \%)$ & $0.2(-71 \%)$ & $0.6(211 \%)$ & $0.009(<1 \%)$ \\
\cline { 2 - 6 } & NOx $+20 \%$ & $18.4(<1 \%)$ & $0.4(<1 \%)$ & $0.7(<1 \%)$ & $0.2(<1 \%)$ & $0.009(<1 \%)$ \\
\cline { 2 - 6 }$-20 \%$ & $18.4(<1 \%)$ & $0.4(<1 \%)$ & $0.7(<1 \%)$ & $0.2(<1 \%)$ & $0.009(<1 \%)$ \\
\hline
\end{tabular}

